\title{
Berichtigungen :
}

Betr. S. 90 Steuerklassen:

Seit 1. 1. 1950 gehören zu Steuerklasse II Unverheiratete, die das 60. Lebensjahr, Verwitwete, die das 50. Lebensjahr vollendet haben.

Betr. S. 103 Wechselsteuer:

Für je DM 600,-- Wechselsumme sind 15 Pfg. Steuern zu entrichten. In unserem Falle müßte der Wechsel mit 45 Pfg. versteuert werden.

Betr. S. 72/73 sachliche Zuständigkeit der Gerichte:

Das Amtsgericht ist zuständig für Streitigkeiten aus vermögensrechtlichen Ansprüchen bis zu einem Streitwert von DM 1000,- .

Das Landgericht ist zuständig für vermögensrechtliche Streitfälle über DM $1000,-$.

Der Magistrat von Berlin (West) führt jetzt nach der neucn Verfassung von Berlin die Bezeichnung ,Sentat". 